\title{
POSTERIOR ANALYTICS II.11, 94b8-26: FINAL CAUSE AND DEMONSTRATION
}

\author{
MICHAIL PERAMATZIS \\ https:/ / orcid.org/0000-0003-2511-5050 \\ Oxford University \\ Faculty of Philosophy / Worcester College \\ Oxford \\ United Kingdom \\ michail.peramatzis@philosophy.ox.ac.uk
}

\section{Article info}

CDD: 185

Received: 14.08.2019; Accepted: 09.09.2019

DOI: http://dx.doi.org/10.1590/0100-6045.2019.V42N4.MP

\section{Keywords \\ Aristotle \\ Final Cause \\ Explanation \\ Demonstration \\ Causation}

\begin{abstract}
I present the text at Posterior Analytics (=APo) II.11, 94b8-26, offer a tentative translation, discuss the main construals offered in the literature, and argue for my own interpretation. Some of the general questions I discuss are the following: 1. What is the nature of the explanatory syllogisms offered as examples, especially in the case of the moving and the final cause? Are they scientific demonstrative explanations? In the case of the final cause, are they practical syllogisms? Are they productive?
\end{abstract}

2. Are we to read into such examples Aristotle's requirements from APo I.4-6 that demonstrative premisses and conclusions are universal, per se, and necessary? If so, in what way? If such requirements do not apply here, what are the implications for question 1 ?

3. What, if any, is the advantage of one type of causal explanation over another (e.g., of final over efficient) in cases in which there is causal competition between complementary explanations? 
4. What is the relation between the thesis of this chapter, especially the section dedicated to the final cause, and the argument of II.8-10? How is essence (the what-it-is) related to causes? How is explanation/demonstration-based definition related to causal explanation in terms of the four causes?

\section{INTRODUCTION}

The aim of the present paper is exegetical. I shall present the text at Posterior Analytics (=APo) II.11, 94b8-26, offer a tentative translation, discuss the main construals offered in the literature, and argue for my own interpretation. Before focusing on the text, however, it is useful to raise a few general questions that are important for understanding not only the present section but also the rest of $A P_{0}$ II.11:

1. What is the nature of the explanatory syllogisms offered as examples, especially in the case of the moving and the final cause? Are they scientific demonstrative explanations? In the case of the final cause, are they practical syllogisms? Are they productive or related to craft/skill?

2. Are we to read into such examples Aristotle's requirements from APo I.4-6 that demonstrative premisses and conclusions are universal, per se, and necessary? If so, in what way? ${ }^{1}$ If such

1 For instance, are the necessary premisses of Aristotelian scientific demonstration analytic and a priori knowable or are they non-analytic, non-a priori knowable? Barnes (1994, 231), for example, thinks that in II.11 Aristotle 'confuses his official analytic conception of explanation with the ordinary notion of explanation which allows it to link events that are separated in time'. This is a claim Barnes has already made in his comments 
requirements do not apply here, what are the implications for question 1 ?

3. What, if any, is the advantage of one type of causal explanation over another (e.g., of final over efficient) in cases in which there is causal competition between complementary explanations?

4. What is the relation between the thesis of this chapter, especially the section dedicated to the final cause, and the argument of II.8-10? How is essence (the what-it-is) related to causes? How is explanation/demonstration-based definition related to causal explanation in terms of the four causes?

\section{INTRODUCING THE FINAL CAUSE: 94B8-12}

\section{Text}

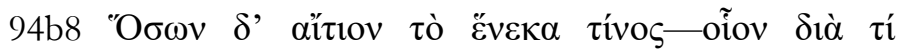

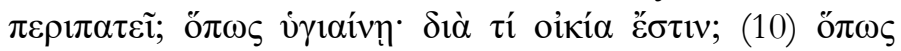

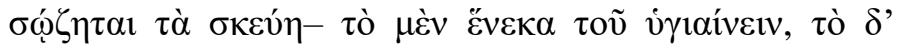

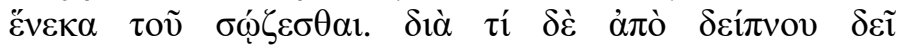

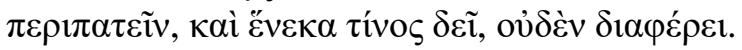

on I.4. But there is no reason to see analytic explanation anywhere in the $A P o$, or at least in any of the interesting cases of book II, such as thunder, eclipse, or deciduousness. Charles (2010, 302-3) makes a similar criticism without mentioning Barnes (his targets are Ferejohn, McKirahan, and Goldin). 


\section{TRANSLATION}

In those cases whose cause is the 'for the sake of what?' -for instance, why does he walk about? In order to be healthy. Why is there a house? In order that our belongings may remain safe. The one is for the sake of being healthy, while the other for the sake of keeping them safe. And 'why should he walk about after dinner?' does not differ at all from 'for the sake of what should he do so?'.

\section{COMMENTS}

The introductory clause is highly elliptical. The beneka tinos is interrogative, as Ross suggests. I have sought to bring this out in my translation but the result is less than elegant.

Interpreters seek to reconstruct the two initial examples as explanatory syllogisms. Presumably, the middle terms should be, respectively, being healthy, and keeping belongings safe. Ross (1949, 642-3) offers the following two options:

Those who wish to be healthy walk after dinner.

This man wishes to be healthy.

This man walks after dinner.

and

Walking after dinner produces health.

This man desires health.

This man walks after dinner.

He also notes that being healthy or health and, generally, the final cause are never middle terms; rather the middle term is something like 'being desirous of health', which is 
an efficient cause. I find it more plausible to take these initial examples merely as illustrating what form the cause takes in such cases: the explanation-seeking question is 'why/for what does he walk about?' or 'why/for what is there a house?' and the explanation-giving answers are, respectively, 'because of being healthy' and 'because of/for safekeeping one's belongings'.

This deflationary reading seems to be confirmed by b1112 , which emphasises that 'why?' questions in such cases are equivalent to, or do not differ from, 'for the sake of what?' explanation-seeking questions. Correspondingly, the answers to such questions suggest that the relevant causes are final causes.

A further question arises about the attempt to recast these initial examples into syllogistic form. As Ross points out, it is difficult to do so without invoking desire or choice. Thus, someone who desires health will walk after dinner because they grasp that postprandial walks bring on health and health is their general intended desire or purpose. Similarly, someone will decide to build (or buy?) a house because they grasp that houses protect their belongings, and their general intended purpose is to safekeep their belongings. But are we to think that Aristotle's main concern in the present context is about such practical or productive syllogisms? They do not seem to be scientific in the sense of universality, necessity, or explanatoriness involved in cases such as thunder or lunar eclipse just discussed in II.8-10 (see question 1 in section 1).

Moreover, in the case of the house are we to invoke a similar example from Metaphysics Z.17, a chapter which anyway has strong affinities to APo II.11? Here is a formulation of the example (even this is extremely controversial!): 
Having a covering structure belongs to being a house (=being for the sake of protection/safety).

Being a house belongs to these types of brick, stone, etc. Having a covering structure belongs to these types of brick, stone, etc.

The middle term of this sample syllogism is the essence of a house, being a house, which is identified with the final cause: being for the sake of protection/safety. I find the strategy of invoking Metaphysics Z.17 to understand APo II.11 unattractive. There is no allusion in APo II.11 to any hylomorphic analysis, which seems to be presupposed in Metaphysics Z.17. Indeed, there is no explicit mention of matter as such and its correlate form anywhere in the Organon.

I conclude that it is more plausible to think that this initial section is an innocuous introduction that illustrates how a cause can be identified with the final cause.

\section{INTRODUCing THE EXAMPLE OF PostPRANDial WALKS: 94b12-18 \\ Text}

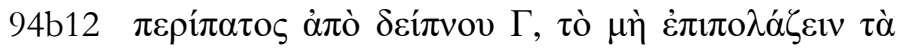

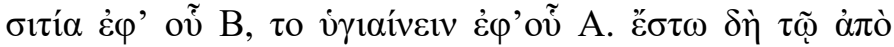

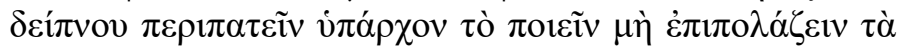

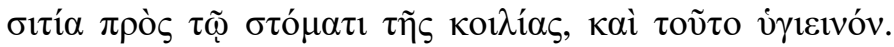

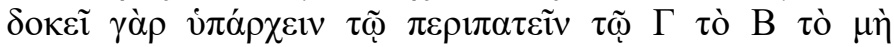

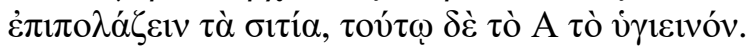

\section{TRANSLATION}

A walk after dinner $\mathrm{C}$, the foodstuffs' not remaining on the surface $\mathrm{B}$, being healthy $\mathrm{A}$. Let us assume that making 
foodstuffs not remaining on the surface at the mouth of the stomach belongs to walking about after dinner, and that this is healthy. It seems that $\mathrm{B}$, the foodstuffs' not remaining on the surface belongs to walking about, $\mathrm{C}$, while A, being healthy, belongs to $\mathrm{B}$.

\section{COMMENTS}

The main general question in the present and the following sections is whether the middle term does, or even can, pick out the final cause, being healthy (or health?).

Lines 98b12-14 simply specify what each of the three syllogistic terms stands for. Let me codify them as follows:
A: being healthy
B: food descent
C: postprandial walk.

It is important to point out that nowhere does Aristotle specify the final cause as health, the relevant general or overall state of the whole living (human?) body. Rather, he uses what could be labelled 'paronymous' terms such as 'being/becoming/keeping healthy (94b9-10; 13; 21: bugiainein) and being healthy/what being healthy is (b16; b17-18: to hugieinon). This may be important for the question of not only what the middle term is but also of how to take the subsequent section (94b18-23). The idea would be that he is focusing not on health generally but on being healthy in a specific way, i.e. being digestively healthy. Moreover, this way of being healthy would presumably be dependent in some way on the general state of health. And perhaps the converse too is the case but in a different way? For instance, being digestively healthy may be thought to be teleologically directed to general health, whereas the latter may partly consist in being digestively healthy. Compare 
how a bodily part and its function(s) are for the sake of, and so are dependent on, the whole body and its function(s). But the whole body, too, depends on its parts: it is made of some or other such parts (even if some of them are replaceable or even dispensable). In what follows I shall assume that being healthy (the referent of the Aterm) in the present context is restricted to being digestively healthy, and that, in turn, being digestively healthy cannot be defined without some reference to the overall healthy condition of the whole body (where this condition is what we would strictly speaking call 'health'). ${ }^{2}$

Let us formulate the syllogism in the first figure (which seems to be implied by what Aristotle writes) without introducing any quantifying phrases as these do not occur in the text -this is not, at any rate, peculiar just to this example: see the efficient cause example given in the preceding section of II.11 (94a36-b8) but also the examples of thunder and lunar eclipse in II.8-10.

\footnotetext{
2 It is tempting to introduce here Aristotle's pet example of an item that is 'said relative to one' central case (pros hen legomenon): what is healthy, being healthy, or even the term 'healthy' (e.g., Metaphysics Г.2, 1003a33-b10). While the context of APo II.11 does not require or imply any reference to this idea, it may be worth noting that, in my view, being healthy or what is healthy could be understood as a certain type of state (that of digestive health) that is pros hen dependent on the general state of health of the whole body. It is not productive, indicative, or symptomatic of the general healthy condition of the body but is partly constitutive of, and teleologically directed to, it. Analogously, it may be thought that a bodily part or organ, say a hand, is a buman hand, and is pros hen related to the whole human body and ultimately the human form in that it partly constitutes this sort of organic or living body and is teleologically dependent on it and, more fundamentally, on its form.
} 
Being healthy belongs to food descent.

Food descending belongs to postprandial walking.

Being healthy belongs to postprandial walking.

Let us label this our 'sample' syllogism. There are two central questions:

(1) Is this a scientific demonstration? Of what science? Perhaps physiology or nutritional science? The kind of explanation and prescription that (e.g.) Milo's trainer would give Milo? If so, it would still be expert knowledge but more akin to craft or skill, and presumably subordinate to medicine.

(2) How are we to read the 'belongs to' or 'holds good of (b14: huparkhon): as a mere predication -e.g., the major premiss would be 'food descent is healthy'or as causal -e.g., the major premiss would be 'food descent brings on a healthy state' and the minor 'postprandial walk brings on food descent'?

If we read the minor premiss predicatively as 'postprandial walking is food descent', we end up with nonsense. The causal reading, in this case, makes better sense. Again (just like in the issue of the absence of quantifying expressions) the causal reading is not an oddity of the present example. In II.8-10, too, we had the quenching of fire bringing on noise, and the earth's screening bringing on light-loss. ${ }^{3}$

${ }^{3}$ In such cases the buparkhein seems to express a causal relation as the attributes said to belong to the relevant subjects are effects of the subjects' condition or activity: for instance, noise is an effect of fire's being quenched; light-loss is an effect of the Sun's light being screened by the Earth; food descent is an effect of postprandial walking. While these examples involve efficient causes and their effects, it is possible to have causal 'belongings' that rely on other types of Aristotelian cause: for instance, a 
The serious problem is, I think, that if we have one premiss using the sense of predicative belonging and another using the sense of causally bringing on, the syllogism borders on (to put it mildly) equivocating on buparkhein and so may well be invalid. Again this is not a problem peculiar to II.11 or the present example. Take the thunder example:

Noise belongs to fire quenching. Fire quenching belongs to clouds. Noise belongs to clouds.

The major premiss in this example is clearly causal -fire quenching brings on noise- while the minor is predicative the clouds have fire being quenched in them. While there are several ways to address this issue of equivocation and invalidity, let me not digress into it. ${ }^{4}$

certain type of covering structure belongs to the sort of protection characteristic of houses in that the former is for the sake of the latter. Ross discusses the ambiguity between predicative and causal belonging (1949, 643). Barnes (1994) takes all these cases as predicative belongings.

4 Prior Analytics I.36 (especially 48a40-b9) may be used to paraphrase the terms and render such syllogisms valid in a more perspicuous way. In that context Aristotle points out that when (for instance) it is claimed that there being one science belongs to contraries, this is not to be taken as implying that contraries are one science. Rather, the premiss would suggest that it is true to say of contraries that there is one science of them. Similarly, it may be argued, in the thunder case we can recast the terms as follows:

Fire, if/when quenched, is such that it brings on noise.

Clouds are such that they have fire being quenched in them.

It is unclear, however, whether there is a common middle term between these two premisses. Nor do we seem to get a decent 
In our digestion-related example one way to get around this problem is to take both premisses causally:

Food descending causes a healthy condition. Postprandial walking causes food descent. Postprandial walking causes a healthy condition.

So understood, however, it is hard to see how the syllogism constitutes a final causation-based explanation. Rather, it seems to be about efficient causation: postprandial walking brings on food descent; food descent brings on a healthy state; so (by transitivity of ' _ to bring on ...') postprandial walking brings on being healthy.

This leads us to the main problem arising from the present section: the middle term in our example is not the final cause, being healthy, but food descent. This has generated significant debate as to how to understand Aristotle's argument and his view of the relation between

conclusion: is the cumbersome claim 'clouds are such that they have in them something that is such as to bring on noise' the intended reading of Aristotle's conclusion 'noise belongs to the clouds'? A more promising (in my view) way to address this problem runs as follows. The major premiss describes a causal process in which a certain efficient cause (quenching of fire) results in a certain phenomenon (noise). The minor premiss states that a certain subject (the clouds) is an active or passive participant in, or underlier of, the relevant causal process: in this case the clouds are the subject in which the fire is being quenched. If so, the conclusion simply brings out the fact that the relevant subject will somehow display the characteristic effect of that process: for this subject suffers by the activity of the efficient cause, and so will exemplify that activity's causal outcome (the noise). This suggests that the objection of invalidity is not decisive. Lewis $(2013,282-7)$ raises this objection in connection with the syllogisms given in Metaphysics Z.17. For a brief discussion of this issue see Corcilius 2019 in the present volume. 
scientific demonstrative explanation and final causation. There are four main options, which I shall set out shortly, but to assess them properly we should consider the rest of the present section, b14-18, as well as the rest of Aristotle's discussion of the final cause in II.11. Here are the options:

(a) Pacius' approach (also followed by Ross, 1949, and D. Charles, 2010, 305-8). The final cause section of II.11 operates on the basis of two syllogistic examples: one of efficient causation, which is the example given at b12-18 and further discussed at b18-20. From b20 onwards, however, there is an implied final causation syllogism, where health serves as a middle term. In this latter section health is taken to be the proper or strict definiens of food descent.

(b) Bolton's approach (1997). There is one syllogistic example here: it is of final causation but the final cause is defined fully in terms of material and efficient conditions, the foodstuffs and their downward motions. Thus, the major premiss just reduces the final cause to material and efficient conditions such as food descent, and food descent just is the relevant final end, the healthy condition. In this way, the middle term is the final cause. But this comes at a cost: the final cause is eliminated in favour of material and efficient causes.

(c) Leunissen's approach (2010). There is one syllogistic example but the middle term is the efficient cause (accompanied with the material cause, e.g., foodstuffs). The final cause does play a role: it is the major term. More subtly, the example is of final causation in that the final cause figures in it and also is the explanatory starting-point in the sense of an observable activity or condition which we use as a springboard to ask 'what brings it on?' 
and to inquire into its deeper scientific causes, which are always material and efficient $(20-1 ; 211)$. Leunissen favours the distinction between aitios/aition as the cause (the item responsible) and aitia as the whole linguistic or epistemic explanation (the account of the accusation; 179182), a point emphasised by Frede (1980) but not ascribed by him to Aristotle. It is unclear whether Leunissen makes the extra move of thinking that Aristotle operates with this semantic distinction. At any rate, this would never work: just see aition at 94b8 used of the final cause, not just the explanation involving the final cause; or 94a20-1 where aitia/ aitiai is used of the four types of cause, and then 94a36 aition used of the formal cause. Moreover, she thinks that final causes are never picked out by middle terms in explanations of natural science (179; 188-9): for, she argues, Aristotelian scientific explanatory demonstrations track the causal structure of the world, while the latter tracks temporal priority. Because final causes are never temporally prior or first, they can never be strict scientific causes. She also separates sharply (not just notionally) not only the final but also the formal cause (essence or form) from efficient and material causes $(13 ; 179-180 ; 200-1)$ : while the final cause is prior in nature and definition, it is not causally or explanatorily prior. Efficient causes, by contrast, are prior in coming-to-be, in time, and so causally too (135-136). Clearly there is a lot to disagree about in this view. Why should we adopt this excessively restrictive, Humean view of causation and impose it on Aristotle? How can the formal cause in natural, living cases (or even in production or action) be specified without the relevant telos? How can the final causes, which are 
prior in nature and definition, be merely startingpoints for an explanatory inquiry, as opposed to grounds or principles from which one demonstratively explains other facts, including material and efficient facts? Apart from such problems, though, if we focus just on our passage, it looks as though Leunissen's view is not a nonstarter: for the middle term does look like an efficient-cum-material item.

(d) There is one syllogistic example and it is a final causation explanation, where the middle term is the final cause. There may also be an allusion to a corresponding or complementary efficient causation syllogism in the final section of II.11 (94b23-6) where Aristotle contrasts final and efficient causation cases. One way in which to develop this suggestion is to assume that, for the purposes of this example, Aristotle supposes that health or being healthy and food descent are convertible and so health ends up in the middle term slot as follows:

Food descent belongs to being healthy.

Being healthy belongs to postprandial walking.

Food descent belongs to postprandial walking.

Here we assume as a minor premiss the plausible claim that postprandial walks are healthy or for the sake of health. From this we deduce that, and explain teleologically why, food descent, B, belongs to postprandial walking, $\mathrm{C}$, which is the explanandum implied by 94b20-1: dia ti de to B tô( $(i)$ $G$ estin. Thus, this interpretation goes, the recast final causation syllogism derives and explains precisely this point. Monte Johnson (2005, 52-56) takes this route of convertibility but his discussion 
is rather brief. He notes, correctly I think, that for the conversion move we do not need to assume that health is identical with or reduced to food descent any more than in the house case safety is identified with or reduced to safekeeping our belongings (54-55). His other case is taken from II.16-17, where for the purposes of his example, argues Johnson, Aristotle takes not just broadleaved trees and being deciduous to be convertible but also figs or vines to be convertible with being deciduous. It is unclear, however, whether this is Aristotle's point in these chapters (see especially II.17, 99a16-29). Johnson does not comment on the difference, discussed in section 3 , between health (bugeia) and being healthy or what is healthy (bugiainein; to bugieinon).

Within view (d), however, in which there is only one syllogism of final causation, we could follow an alternative strategy: while the final cause, being healthy, figures as a middle term in that it is defined in terms of food descent, it is not fully reduced to, or identified with, efficient-cummaterial conditions. At least such non-teleological conditions are not the whole story. It may be that the efficient-cum-material conditions (e.g., food sinking) are incomplete without invoking the telos of overall health of the whole living (human?) body. Importantly, this view need not rely on any conversion of terms in the major premiss to render the final cause a middle term.

I am attracted to view (d) but not in Johnson's version. Rather, as I noted in section 3, it seems more plausible to think that in the present context being healthy is restricted to just digestive health. Further, while being digestively healthy is defined as food descent, this latter contains an ineliminable 
(implicit) reference to the telos of overall health of the whole body. There is no need, then, for any conversion as the middle term just is the same as being healthy -food descent just is the definition of that way of being healthy (digestively) - and is itself irreducibly telic. It should also be noted that my preferred reading is philosophically congenial to (a), especially in that it treats digestive health, understood in terms of food descent, as essentially dependent on the telos of the overall health of the whole body. The main difference is in respect of exegetical economy: my interpretation does not require us to extract two syllogisms from Aristotle's brief and obscure text; further, it offers a more plausible (or so I shall argue) reading of 94b18-23, especially Aristotle's remarks about definition (bösper ekeinon logos; to $A$ boutōs apodothesetai; tout' esti to hugiainein); finally, it makes better sense of Aristotle's claims about temporal priority and posteriority at 94b23-6.

We should discuss the rest of the section on final causation to have a clearer idea about and assess the different options.

94b14-16: estô dê... kai touto bugiainein. It is unclear whether this sentence spells out or fills in the details of our sample syllogism as it stands or whether it introduces some further considerations. One reason for thinking that it makes an extra point is the introductory estô: let it be (assumed) that... This may indicate that Aristotle explains the background of his example or sets out his presuppositions. Another reason is that we do not have the B-term with the content just specified -food descent- but rather making (poein) foodstuffs not remain on the surface at the mouth of the stomach. Indeed, the description of the phenomenon is far richer here as we are given information 
about the stomach and its mouth. It may be that this background assumption is not part of the final causation syllogism but of the complementary efficient causation explanation: postprandial walking brings on food descent from the surface at the mouth of the stomach.

On the other hand, the minor premiss of our sample syllogism -food descent belongs to postprandial walking-if cast in subject-predicate order, is most naturally read as 'postprandial walking brings on food descent'. But perhaps there is no reason to formulate this premiss in subjectpredicate order. Perhaps it is important that we retain the predicate-belongs-to-subject order.

b16: kai touto bugieinon: the reference of touto seems to be to food descent. Thus, food descent is healthy. This may be read as simply codifying the major premiss in our sample syllogism: being healthy belongs to food descent. Alternatively, it could be read as part of the background assumption -estô dê...- and as continuing the complementary efficient causation explanation: food descent brings on a healthy state; postprandial walking brings on (hence, the use of poiein) food descent; hence, postprandial walking brings on a healthy state.

It is important also to point out that we have already had a couple of important efficient causation explanatory demonstrations: thunder and eclipse. Neither seems to have the structure just deployed. Rather, while the major premiss uses the 'bringing on' sense of belonging (fire quenching brings on noise; the earth's screening brings on light-loss), the minor is about the subject that undergoes a relevant change (the clouds' having fire quenched in them; the moon's having the earth screening the sun's light). Hence, it may be that the estô dê... sentence does not correspond to either a final causation or an efficient causation syllogism. Rather, it encapsulates just (an) auxiliary assumption(s).

b16-18: dokei gar... to A to bugieinon. The gar here could be explanatory ('for...') or could be just resuming the 
discussion of the example from b12-14, now better understood in the light of the estô dê... sentence at b13-16. Presumably, this latter sort of gar would be what Denniston $(1950,67)$ calls the appositional use of gar, which is an extension of the explanatory use: 'indeed', 'that is to say', 'to wit'. Notice that the specification of the B-term shifts back to foodstuffs' not remaining on the surface, as at b13, with no mention of the stomach or its mouth nor, more importantly, any mention of poiein. Generally, it seems hard to see how this sentence explains the previous one. Another idea might be that the estô dê... clause is parenthetical and the gar takes up the sentence specifying the content of the syllogistic terms at b12-14. In this case it could be rendered either as explanatory: 'for, given the terms just specified, it seems that...'; or again appositional: 'that is/indeed, in the light of the terms just given, it seems that...'. There is not much progress in the argument being made in these lines. They just lay out first the major and then the minor premiss of our sample syllogism.

\section{DEVELOPING THE EXAMPLE: 94b18-23 Text}

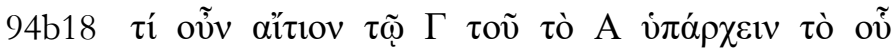

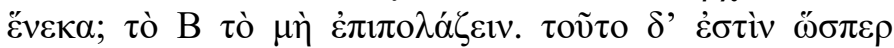

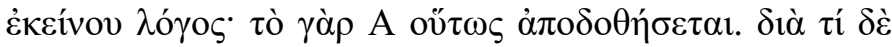

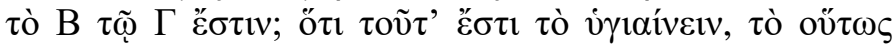

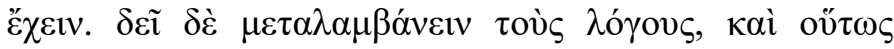
$\mu \tilde{\alpha} \lambda \lambda \mathrm{ov} \varepsilon \check{\kappa} \kappa \alpha \sigma \tau \alpha$ $\varphi \alpha v \varepsilon \tilde{\tau} \tau \alpha$ l.

\section{TRANSLATION}

What, then, is the cause for $\mathrm{C}$ of $\mathrm{A}$, the 'that for the sake of which', belonging to it [i.e. to C]? B, the foodstuffs' 
not remaining on the surface. And this [i.e. B] is just as [or: as it were?] the account of that [i.e. A]; for A will be spelt out in this way. And why is B [a cause?] for C? [Alternatively: and why does B belong to C?] Because this is what being healthy is, to be in such a condition. But we must take the accounts instead [or: we must convert the logous], and in this way everything will become clearer.

\section{ComMenTs}

b18: ti oun to aition... to hou heneka. This seems to be an explanation-seeking question that corresponds to the conclusion of our sample syllogism: being healthy belongs to postprandial walking. The sample syllogism, then, ought to not only derive but also to explain the relevant connection $\mathrm{A}-\mathrm{C}$. The role of being healthy as the final cause is consolidated here, despite the fact that it is not picked out by the middle term. In fact, the explanationgiving answer at b19 seems to identify the middle term, B, and so the cause, with food descent -hence, the interpretations in which this is either the efficient causation syllogism, with the final causation syllogism to come (a), or this is the final causation syllogism, with the final cause being reduced to efficient-cum-material conditions (b), or this is just the efficient causation syllogism, with no final causation syllogism to come (c).

Lines b19-20, however, introduce a further complication: clearly touto refers to food descent, B -as this is the most proximate item- while ekeinou refers to A, being healthy, the final cause, which is the more remote item. Moreover, the subsequent gar clause takes the definiendum (or quasi-definiendum, depending on our view of hôsper) to be A, being healthy. Hence, $\mathrm{B}$, food descent is the account of A, being healthy; or being healthy, A, is somehow 
defined (apodothêsetai) as food descent, where houtôs picks out $\mathrm{B}$, food descent.

How are we to understand the 'somehow' in 'somehow defined'? How are we to take the hôsper in hôsper A's logos? Many interpreters translate hôsper logos with 'as it were, an account' or 'like an account' (Ross 1949, 643; Barnes 1994, 60; Charles 2010, 306). Charles argues that B is only an 'as it were' account of A because food descent cannot be the proper definiens of health (the general healthy condition of the whole body, I take it; he does not comment on the differences between health, becoming/being/keeping healthy, and what is healthy). For health is irreducibly telic, while food descent is just an efficient-cum-material condition. Hence, he contends, b20ff. marks the transition to the final causation syllogism, where B itself, food descent, will be defined properly as being teleologically directed to health. Hence, lines b21-3 offer the proper definition of food descent, $\mathrm{B}$, in terms of health.

The alternative is to take the hôsper more strongly: 'just as/just like' or even 'just is'. Indeed, the subsequent gar clause at b20 does not seem to attenuate in any way the manner in which A, being healthy, is defined in terms of B, food descent -unless we think that apodothêsetai implies 'being quasi-defined' as opposed to a boristhêsetai, which would suggest 'being strictly defined'. Similarly, if we take b21 to be specifying the definition of $\mathrm{A}$, to bugiainein, in terms of touto $=\mathrm{B}=$ to boutôs ekhein = having food sink in one's stomach, then again there does not seem to be any weak or 'as it were' notion of definition at play.

If we take this latter approach, we could adopt option (b) -where the final cause is wholly reduced to efficientcum-material conditions- or (d) -where the final cause is defined in terms of material and efficient conditions. Again in (d) the idea might be either that the major premiss is to be converted or that the definition of being digestively healthy in terms of efficient-cum-material conditions 
contains an irreducible telic component, the general health of the whole body. By contrast, view (c) operates on the assumption that the final cause is never explanatorily or causally basic, so it seeks to emphasise that being healthy is somehow reduced to efficient/material causation. Pacius' line, also followed by Charles, favours the alternative, 'as it were' reading. ${ }^{5}$

b20-1: dia ti de to B tô(i) G estin. Does this mark a shift to a different syllogism, where the explanandum and so the conclusion is not $\mathrm{A}-\mathrm{C}$ but $\mathrm{B}-\mathrm{C}$, i.e. that food descent belongs to postprandial walking? The explanation-seeking question dia ti... estin corresponds exactly to this explanandum conclusion. If there is such a shift, the implicit syllogism would have as its middle term being healthy, and so the final cause would be picked out by the middle term.

The hoti tout' esti to hugiainein, to houtôs ekhein at b21 would offer the explanation or cause. It would imply that the middle term picks out being healthy, the final cause. Charles, I think, takes touto to be referring to B, food descent, but also to be the definiendum: food descent is (definitionally) to be healthy. But I think that it is at least equally natural, if not more so, to take to bugiainein -what seems to be the subject of the clause- as the definiendum and the touto, referring to $\mathrm{B}$, food descent, to be the definiens. In this reading the clause would be invoking the same definitional connection as that just introduced at b1920: being healthy (in the digestive mode) $=_{\text {def }}$ food descent

5 Corcilius (2019, present volume) renders ekeinou logos and apodothèsetai in a different way (which is not, I think, incompatible with my reading): he maintains that $\mathrm{B}$, food descent, is more precisely a realiser of $A$, (digestive) health, while $C$, postprandial walking, is the productive cause of the realiser, $\mathrm{B}$. He goes on to argue that this explanatory structure underlies all genuine Aristotelian teleological explanations. 
of a certain type (understood in the manner outlined in section 3).

If, on the other hand, there is no shift to a different syllogism, Aristotle would be asking what grounds the connection in the minor premiss of our sample syllogism: B-C. Where or how do we get the premiss that food descent belongs to postprandial walks? The answer would then be as follows: $\mathrm{B}$ belongs to $\mathrm{C}$ because $\mathrm{B}$ defines health. But this would not make good sense. Would the idea be that we should replace $B$ with its definiendum, $A$, and get a clear reason why $\mathrm{B}-\mathrm{C}$ holds, i.e. because it is effectively the same as $\mathrm{A}-\mathrm{C}$ ? This latter, however, is the conclusion of our sample syllogism: it can hardly be used to explain the minor premiss.

An attractive alternative would be to render the sentence dia ti de to $B$ tô(i) $G$ estin in the way Barnes does: 'why is B explanatory for C?'. In a more literal and expanded fashion: 'why is $\mathrm{B}$ the cause for $\mathrm{C}$ of $\mathrm{A}$, being healthy, belonging to it, i.e. C?'. Barnes concedes that this is a repetition of the question raised at b18 ti oun to aition tô( $i)$ $G$ tou to $A$ buparchein to hou beneka. I do not think that this pessimistic diagnosis is necessary. The later question would have a subtly different point than that of the earlier question. The earlier question was 'what is the cause for A - C?', whereas the later question makes some progress: 'assuming that the cause is identified as B, what is so special about B that it can play this basic role - why is B the cause?'. Answer: it explains why A, being healthy, belongs to C, postprandial walking, because $\mathrm{A}={ }_{\operatorname{def}} \mathrm{B}$, and $\mathrm{B}$ has just been assumed in the minor premiss to belong to $\mathrm{C}$, so its definiendum, A, also belongs to $\mathrm{C}$. This is more satisfactory. I think that anyone who holds that there is no shift to another syllogism at this juncture ought to follow this line.

b21-3. Perhaps if we knew what Aristotle means by the phrase metalambanein tous logous, everything would indeed 
become clearer, as he says, but, as it stands, this phrase is ambiguous as between 'substituting the accounts/definitions for something else', presumably the name of a definiendum, and 'converting the logous'. The latter is of course how convertibility interpreters, such as Johnson, take the phrase. It would be difficult in that case to render it 'converting the terms' as logous can hardly mean the same as 'terms'. But perhaps we can understand logous as statements: specifically the staments used as premisses in our sample syllogism, especially the major premiss. The injunction would be: "convert "being healthy belongs to food descent" into "food descent belongs to being healthy". This, presumably, would be permissible because food descent defines being healthy. This convertibility reading arises from the use of metalambanein as 'to take something differently'; here 'to take the order of the terms in a premiss differently'. Commentators cite $A P r$ I.17, 37b15, and II.4, 56b8, for this use of metalambanein.

The substitution reading of metalambanein seems more attractive. It grows out of the use of this term for 'to take something instead of something else', where a logos is usually taken instead of something else, normally a name (Top. V.2, 130a39; VI.4, 142b3; 9; 147b14). How to apply this use in the present context depends on one's overall approach. Pacius-style (a) readers think that it marks the shift to the final causation syllogism and suggests that we should give the proper (as opposed to the 'as it were') definition of food descent in terms of health or being healthy. By contrast, (b), (c), and (d) interpreters take this sentence to be summarising and highlighting the importance of the points made at b19-21 about the definition of being healthy in terms of food descent: 'once you take this definition instead of the isolated term "being healthy", then it will become clearer how the explanation works, why the final cause explains the conclusion, and how this sort of cause is indeed picked out by the middle 
term' (if it is indeed so picked out: (c)-style readers would deny that it is).

\section{The Contrast With EfFicient Causation DEMONSTRATIONS: 94b23-26}

\section{Text}

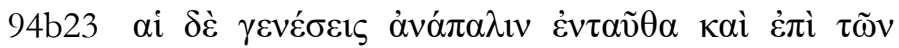

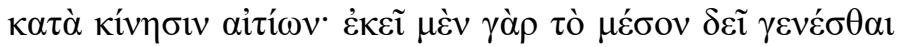

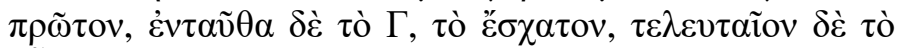

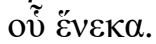

\section{TRANSLATION}

But here things occur in the reverse order compared with change-related causes; for there the middle term must occur first, while here $\mathrm{C}$, the ultimate term, occurs first, whereas the 'that for the sake of which' occurs last.

\section{COMMENTS}

Clearly this section contrasts efficient with final causation explanatory syllogisms in respect of the temporal order in which certain terms, especially the middle term, come to hold of other terms. Unsurprisingly, interpreters disagree about the details. Interpreters of type (a) argue that this section contrasts the previous efficient causation syllogism -our sample syllogism- with what they take to be the recently introduced final causation syllogism (b20-3), where being healthy is the middle term and is explanatory of some conclusion such as B-C. Hence, the two entautha at b23 and 25 pick out the implicit syllogism with the middle term being healthy, the epi kata kinêsin aition picks 
out as an example our sample syllogism with the middle term food descent (an efficient cause), and ekei at b24 similarly picks out our sample syllogism. This reading would render accurately the description of the final causation syllogism: C, postprandial walking, is first in time, while A, being healthy, temporally last. The difficulty, however, is that this reading would make the description of what it takes to be the efficient causation syllogism problematic: the middle term there is food descent and this does not occur first; rather, postprandial walking occurs first, and then food descent.

Another way to take the referents of epi kata kinêsin aition and $e k e i$ is not as picking out the digestion-related example at all but as contrasting the entautha case -final causation syllogisms- with the previous section of II.11, which discussed efficient causation syllogisms: e.g., the Athenians' being warred upon (94a36-b8; Ross 1949, 637; 645; but contrast 644). There, indeed, the middle term, a prior attack by the Athenians with the Eretrians, happened first. This would then contrast with the fact that the middle term here -being healthy or/and food descent, depending on our interpretation- occurs temporally last though it is explanatorily primary, whereas the minor term, C, postprandial walk, occurs first in time. ${ }^{6}$

6 There are different ways in which to interpret 94b23-6. In an unpublished paper on APo II.11 Lucas Angioni (2015) compares this section with Metaphysics Z.7, 1032b15-30. Using this latter passage, he takes the case of hai geneseis (94b23) in a very general sense that covers both physical processes, where efficient causes operate, and teleological reasoning. He goes on to argue that we need not take dei genesthai prōton (b24-5) as implying that the middle term must be first in the three-term series. Rather, this phrase can be taken to suggest that the middle term must come first relative to just the major term (excluding the minor term, which is common to both syllogisms under consideration). 
Even if we take the contrast to be with the previous section, still we could think that there is an implicit efficient causation syllogism in the digestion-related case too. Even more so if we think that the contrast is between efficient and final causation syllogisms within the digestion-related case. But if so, we would have to come up with a syllogism that does indeed have a middle term that not only is an efficient cause but also occurs first, as opposed to our B, food descent, which occurs after postprandial walking.

What would this efficient causation syllogism look like? First, let us take seriously the idea that the type of explanation in this section of II.11 is cognate with explanations associated with medicine or other skills/crafts such as nutritional expertise. Second, let us model the relevant efficient causation syllogism on the examples of thunder or lunar eclipse, which are paradigmatic efficient causation demonstrations. My suggestion, then, would run as follows:

Food descent belongs to postprandial walking. Postprandial walking belongs to the recent eater. Food descent belongs to the recent eater.

Here the middle term is indeed occurring temporally first. And it causes or brings on by way of efficient causation food descent (major premiss). The minor term is the subject -in the manner of the clouds or the moon- that undergoes or suffers a change, postprandial walking -just like the clouds suffer fire quenching or the moon has the earth screen the sun's light from it. This causal process terminates in its participants (the subjects: recent eater; clouds; moon) having the characteristic affection(s) it brings about: food descent; noise; light-loss. It is an added merit of this proposal that food descent, understood as the relevant (digestive) way of being healthy, is also the final cause that explains why postprandial walking is prescribable 
on the basis of the relevant final causation syllogism just discussed in sections 3 and 4 .

Let me close by returning to question 3 raised in section 1. This question also touches on issues arising in the subsequent section of II.11 (94b27-37). What, if any, is the advantage of final over efficient causation explanation in cases such as our digestion-related example, in which there is causal competition between complementary explanations? We can imagine cases which could be described by the efficient causation syllogism just formulated, where the efficient cause, postprandial walking, brings on the condition of food descent by some sort of deviant causal route (or incidentally, in Aristotelian terminology). For instance, the walker aimed at exercising his/her legs or at improving his/her cardiovascular health, but his/her walking achieved food descent and/or digestive health by chance. ${ }^{7}$ In other cases, postprandial walking for the sake of exercise or cardiovascular health may be too quick, too long, or following too steep a path. In such cases it is likely that this sort of postprandial walking would interfere with, interrupt, hinder, etc. food descent and/or digestive health. It seems that in such cases postprandial walking is not aimed at food descent or/and digestive health but has a different telos. The final causation syllogism is important, then, for it shows how the final cause, food descent or/and digestive health, not only explains the occurrence of postprandial walking but also makes it the type of postprandial walking it is: one that is aimed at this particular state of food descent, which is

\footnotetext{
7 Whether food descent and digestive health are two distinct items (in which case 'food descent and digestive health' seems appropriate) or whether they are somehow the same (in which case 'food descent or digestive health' seems suitable) depends on which general interpretative line one follows among (a), (b), (c), or (d).
} 
intimately linked -in my favoured view, definitory of- the relevant (digestive) healthy state. Aristotle's view of the relation between cause and essence, as well as between explanatory demonstration and definition, answers the "why is it as it is?' and 'what is it?' questions at the same time using the very same resources: essences that are inextricably and ineliminably causal in some or other among the four types of Aristotelian cause. ${ }^{8}$

\section{REFERENCES}

ANGioni L. (2015), 'Posterior Analytics II.11: Final Causation and Its Syllogistic Expression', unpublished draft.

BARnes J. (1994), Aristotle: Posterior Analytics, Oxford: Oxford University Press.

BOLTON R. (1997), 'The Material Cause: Matter and Explanation in Aristotle's Natural Science' in Kullman W. and Follinger S. (eds.), Aristotelische Biologie, Stuttgart.

ChARles D. (2010), 'Definition and Explanation in the Posterior Analytics and Metaphysics' in Charles D. (ed.), Definition in Greek Philosophy, Oxford: Oxford University Press.

Corcilius K. (2019), "Teleology of the Practical in

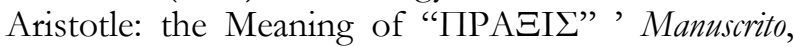

8 An earlier version of this paper was presented at the 2019 European Society for Ancient Philosophy meeting in Athens, Greece, and the 2019 Southern Association for Ancient Philosophy meeting in Oxford. I am indebted to the participants for their comments and questions. I am also grateful to the editors of the present volume of Manuscrito, Lucas Angioni and Breno Zuppolini. 
Special Issue: Aristotle on Science and Its Logical and Metaphysical Entanglement.

Denniston J. D. (1950), The Greek Particles, Oxford: Oxford University Press, $2^{\text {nd }}$ edition.

Frede M. (1980), 'The Original Notion of Cause' in Schofield M., Burnyeat M., and Barnes J. (eds.), Doubt and Dogmatism: Studies in Hellenistic Epistemology, Oxford: Oxford University Press.

JOHNSON M. R. (2005), Aristotle on Teleology, Oxford: Oxford University Press.

LEUnissen M. (2010), Aristotle's Science of Nature, Cambridge: Cambridge University Press.

LEWIS F. (2013), How Aristotle Gets by in Metaphysics Zeta, Oxford: Oxford University Press.

Ross W. D. (1949), Aristotle's Prior and Posterior Analytics, Oxford: Oxford University Press. 